\title{
The Reliability and Validity of World Health Organization Quality of Life Assessment Instrument in Elderly Patients with Hearing Loss: Depending on Use of Hearing Aid
}

\author{
Sungil Park \\ Department of Speech Pathology Therapy and Aural Rehabilitation, Woosong University, Daejeon, Korea
}

\author{
청력손실이 있는 노인에서 세계보건기구 삶의 질 척도(WHOQOL-BREF)의 신뢰도와 타당도: \\ 보청기 착용 유무 \\ 박 성 일 \\ 우송대학교 언어치료청각재활학부
}

\begin{abstract}
Purpose: Presbycusis is a common disorder and may contribute to the development of some psychiatric problem in the elderly, resulting in social -isolation. The purpose of this study was to identify the quality of life of hearing impaired who use hearing aids and hearing aid non-users through World Health Organization Quality of Life Questionnaire (WHOQOL). We measured the reliability and validity of the World Health Organization Quality of Life Assessment Instrument (WHOQOL-BREF) in elderly individuals with hearing loss. The main purpose was to find out whether WHOQOL-BREF is a good measurement or not for quality of life in elderly with hearing loss. Methods: Sixty-two elderly individuals with hearing loss aged sixty years or more participated in the study. They were recruited from a hearing aids center or social welfare facilities. Participants were divided into two groups: non hearing aid users and hearing aid users. WHOQOL-BREF, which is a short version of the WHOQOL, consisted of 26 questions. Among them, 2 questions were about general quality-of-life and the rest of them were associated with four aspects: physical, psychological, environmental, and social relations. The scores of this inventory were compared between the two groups. Results: Significant differences were observed in the only overall score for quality of life between two groups $(p<0.05)$, but no significant differences were observed in other factors. The overall reliability was Cronbach's alpha was 0.76 for hearing aid users and Cronbach's alpha was 0.56 about hearing aid non-users. Conclusion: The result of this study suggested that it is not appropriate to use Korean WHOQOL-BREF for measuring the quality of life for elderly people with hearing loss because it doesn't have good internal consistency.
\end{abstract}

Key Words: World Health Organization Quality of Life Assessment Instrument, Hearing loss, Hearing aid, Quality of life.

Received: January 22, 2016 / Revised: February 18, 2016 / Accepted: March 11, 2016

Correspondence: Sungil Park, Department of Speech Pathology Therapy and Aural Rehabilitation, Woosong University, 171 Dongdaejeon-ro, Dong-gu, Daejeon 34606, Korea

Tel: +82-42-630-9224 / Fax: +82-42-630-9229 / E-mail: psiyes@naver.com

\section{INTRODUCTION}

현재 우리나라는 초고령 사회로 이미 진입한 상태이다. 통계 청에 따르면 2015년 고령인구의 총 인구는 $13.1 \%$ 로 매년 증가하 는 추세이고 2060년에는 40\% 수준으로 전망하고 있으며(Statistics Korea, 2015), 유엔에 의하면 한국 인구의 65세 이상 구성
비는 2010년 $11.0 \%$ 에서 2050년 38.2\%로 크게 높아질 것으로 전망하며, 80세 이상 고령인구의 비중은 2010년에는 $1.9 \%$ 로 선 진국(4.3\%)보다 낮지만, 2050년에는 $14.5 \%$ 로 선진국(9.5\%) 수 준을 상회할 것으로 전망했다[United Nation (UN), 2005].

노인인구의 급증은 우리 사회에 큰 짐으로 다가서고 있다. 문 제는 노인이 되면 여러 가지 기능적인 면이 젊었을 때보다는 떨 
어진다는 것이다. 여기에 청력손실까지 발생하게 되면 자기 스 스로 어떤 문제를 해결하는 독립적인 부분과, 생활 능력에서 많은 어려움이 발생되고, 특별히 다른 사람들과의 의사소통 부 분에서 많은 문제점이 생기게 되어 자연스럽게 따로 생활하게 된다. 이러한 부분이 우울증이나 정신적인 문제로까지 발전하 게 만든다. 최근에는 청력손실을 가진 노인의 경우 치매가 올 확률이 최대 5 배까지 높다는 연구 결과가 있다(Lin et al., 2011). 이는 청력손실에 대한 관심이 증가하고 있다는 증거가 될 수 있 다. 즉, 청력손실이 있는 노인의 경우 노인의 특성에서 듣는 부 분까지 문제가 되기 때문에 노인의 삶의 질에 지대한 영향을 줄 것이다(Kang \& Lee, 2006). 사람은 의사소통 수단으로 말을 사용하고, 통용하는 말을 통해서 다른 사람들과 마음, 생각, 지 식 등을 주고받고 공유한다. 그러나 노인 연령에 들어서서 정도 의 차이는 있더라도 사람들의 말을 듣고도 알아차리기 힘들어 지고, 기억하기도 어렵게 된다. 즉, 난청이 있으면 사람과의 의 사소통에 문제가 생기고 사람으로부터 멀어지게 되면 우울증 과 치매 증상이 나타날 수도 있고, 이러한 부분이 심리적이든, 사회적이든 삶의 질에 지대한 영향을 미칠 수 있다는 것이다. 문제는 이러한 청력손실이 있는 노인을 대상으로 삶의 질을 정 확히 평가하기는 여러 가지 제약이 따를 수 있는데, 가령 나이 의 변수만 생각하면 쉽게 생각할 수 있으나, 청력손실이라는 요 인이 영향을 줄 수 있게 되고 이러한 청력손실이 삶의 질을 평 가하는 데 변인된 요인으로 영향을 줄 수 있게 된다는 것이다.

삶의 질을 측정하는 도구로 최근에 많은 연구들이 활발하게 진행되고 있다. Short Form Health Survey(SF-36) 측정도구도 이 중에 하나이다(Lim, 2006). 하지만, SF-36 도구는 주로 건 강에 기반을 둔 측정도구로 다차원적인 삶의 질을 포괄적으로 측정하는 데에는 한계가 있다. 그러나 World Health Organization Quality of Life Assessment Instrument (WHOQOL, 1998)은 전반적인 삶의 질을 평가하는 도구로 널리 보급되어 사용되고 있으며, 전반적으로 신뢰도와 타당도가 우수한 것으 로 알려져 있고, 국내에서도 번역되어 표준화된 한국판(Min et al., 2002)에서도 그 신뢰도와 타당도에 있어서 다른 나라와 비 교해 비슷한 정도를 나타내고 있다. 이러한 WHOQOL은 삶의 질을 신체적 건강 영역(physical health domain), 심리적 영역 (psychological domain), 사회적 관계 영역(social relationship domain), 환경 영역(environmental domain) 등 6개의 영역으 로 나누어져 있으며, 각각의 영역에는 2 4개의 하부척도가 있 으며 각 하부척도들은 4 개의 문항으로 구성되어 있다. 이들은 총 24 개의 하부척도와 전반적인 삶의 질과 건강에 관해 다루 는 4 개의 일반적인 질문을 포함한다. 이 중 세계보건기구 삶의 질 척도 단축형(WHOQOL-BREF)은 WHOQOL의 24개 하 부척도 각각으로부터 한 항목씩 선택되어 구성되어 있다. 26개
항목은 각각 5 지선다형으로 5점대 척도로 되어 있어 "전혀 아니 다"는 1점, "약간 그렇다"는 2점, "그렇다”는 3점, "많이 그렇다" 는 4점, "매우 많이 그렇다"는 5점으로 채점하고 점수가 높을수 록 삶의 질에 대한 긍정적인 반응이다. 또한 각 영역의 점수를 4 20점대 또는 0 100점대 척도로 변환할 수 있다. 각 영역별 로 세분화되었고 많은 연구를 통해서 검증된 WHOQOL을 통 해 본 연구에서도 난청을 가진 노인을 대상으로 삶의 질을 측 정하고자 한다.

본 연구에서는 앞에서 보고된 것처럼 WHOQOL-BREF는 전반적인 삶의 질을 평하기에 좋은 척도이다. 따라서 $\mathrm{WHO}-$ QOL-BREF가 청력손실을 가진 노인에서도 삶의 질을 정확히 평가하는지 그 신뢰도와 타당도를 살펴보아 만약 타당하지 않 으면 보다 적합한 도구의 개발을 위해 어떠한 요인들이 필요한 지 보고자 한다. 또한 난청이 있는 사람의 경우 보청기를 착용 하면 삶의 질이 높아진다는 선행 연구 결과들이 있다. 국문화한 Korean version SF-36 (Han et al., 2009)으로 검사한 결과 청력 상태에 따른 삶의 질에서 보청기를 사용하지 않는 노인이 신체 적 기능, 정신적 건강, 건강상태 변화 관련 삶의 질이 유의하게 낮은 것으로 나타났으며, 청각장애 정도에서 정상인 노인이 신체 적 기능 관련 삶의 질이 유의하게 높은 것으로 나타났다(Kim, 2009). 청력손실이 있지만, 보청기를 통해서 삶의 질이 개선이 되고 변화된다면, 청력손실이 있는 노인에게 최대한 빠른 보청 기 착용을 통해 삶의 질을 개선하는 것이 바람직할 것이다. 따라 서 보청기를 착용한 노인과 착용하지 않은 노인과의 삶의 질 비 교를 통해 삶의 질을 개선하기 위한 대안 중에 보청기가 그 역 할을 하는지에 대한 부분도 살펴보기로 한다. 마지막으로 인구 통계학적인 요인에 따른 WHOQOL-BREF가 어떠한 차이가 있는지에 대해서 분석하여 어떤 요인들이 청력손실이 있는 노 인의 삶의 질에 영향을 미치는지에 대해서도 분석하고자 한다.

\section{MATERIALS AND METHODS}

\section{연구 대상}

부산 지역에 거주하는 60 80대 이상(평균: 64세) 난청을 가 진 노인 62명(남자: 33명, 여자: 29명)을 대상으로 하였으며, 39 명은 보청기를 사용한 노인이며, 23명은 보청기를 사용하지 않 은 노인이었다. 대상 노인의 청력손실은 pure tone audiometry (PTA) 6분법인 $500+2(1,000)+2(2,000)+4,000 \mathrm{~Hz} / 6$ 으로 계 산을 하였고 PTA가 $20 \mathrm{~dB}$ 이상인 사람을 선정하였고, 청력손 실을 제외한 다른 질환은 없는 사람으로 분류하였다. 또한 연 구의 정확성을 위해 모든 변수, 즉, 경제수준, 거주지역, 성격 등 의 변수를 통제하면 좋으나 연구의 제한점으로 모든 부분을 통 제할 수는 없지만, 정신적인 부분으로 평가에 잘못된 기입이 
될 수 있기에 정확한 삶의 질 평가를 위해 우울증 평가 방법인 Beck's Depression Inventory-II 검사 도구(Beck et al., 1996) 를 가지고 인터뷰를 통해 raw score가 13 이하로 우울증이 없 는 노인을 대상으로 하였다.

\section{연구 절차}

순음청력검사(PTA)는 주파수 $500,1,000,2,000,4,000 \mathrm{~Hz}$ 에 서 보청기 센터와 복지관에서 실시할 경우는 순음청력검사 장비 (Amplivox 260, Oxfordshire, UK)를 이용하여 조용한 방(40 $\mathrm{dBA}$ 이하)에서 기도 검사를 하고, PTA는 청각장애 분류법인 6 분법인 $500 \mathrm{~Hz}, 1000 \mathrm{~Hz} \times 2,2,000 \mathrm{~Hz} \times 2,4,000 \mathrm{~Hz}$ 로 하였 다. 검사에 참여한 노인들에게 검사의 목적과 개요를 설명하고 검사참여에 동의서 서명을 구한 후 WHOQOL-BREF의 설문 지로 측정하였다. 삶의 질 설문은 한국판 WHOQOL-BREF (Min et al., 2002)지침서를 사용하였다. 모두 26문항으로 이루 어진 설문을 사용하였으며 환자가 직접 기록하는 것을 원칙으 로 하였으나, 모두 60 대 이상의 노인임을 감안해 연구자 1 명이 함께 참석해 설문지 작성을 돕도록 하였다. 설문 문항에 하나라 도 누락이 된 설문지는 분석에서 제외시켰다. 이 측정도구는 신 체적 건강영역 7문항, 심리적 영역 6문항, 사회적 관계영역 3 문 항, 생활환경영역 8 문항 등 4 개 영역 26 문항으로 5 점 척도로, 23 개의 긍정문항과 3 개의 부정문항으로 구성되어 있고, 점수가 높 을수록 삶의 질 정도가 높은 것을 의미한다. 전반적인 삶의 질 은 전반적인 삶의 질과 건강상태를 합한 값으로 각 개인이 전 반적으로 느끼는 삶의 질을 나타낸 값이다. 전체 평균 삶의 질 점수(QOL score)는 각 영역별을 전체적으로 합한 값에서 평균 으로 나눈 값으로 전체적인 삶의 질 점수를 볼 때 사용된다. 또 한 4 20점대 또는 0 100점대로 변환해서 사용하는 경우가 있 는데, 각 하부척도가 4개의 항목으로 이루어져 있으므로 모든 하부척도의 점수는 4 20 사이이며, 필요에 따라서 하부척도 점수를 0 100 척도점수로 변환해야 할 때는 0 100점으로 변 환해서 사용한다.

첫 번째 그룹인 보청기를 사용하지 않은 사람은 난청이 있은 이후 한번도 사용한 적이 없었고, 두 번째 그룹인 보청기를 사 용한 사람은 1년 이상 보청기를 사용하고 있으며, 보청기 센터나 병원에서 보청기가 자신의 청력에 맞게 잘 맞춰진 사람이며, 간 략한 인터뷰와 보청기 만족도 척도인 Abbreviated profile of hearing aid benefit를 통해 보청기 만족도가 보통 30점 이상 향 상된 사람으로 하여 어느 정도 보청기 효과를 본 사람을 대상 으로 하였다.

\section{자료 분석}

통계분석은 윈도우용 SPSS (version 14.0; SPSS Inc., Chicago,
$\mathrm{IL}, \mathrm{USA}$ ) 프로그램을 사용하여 먼저 WHOQOL-BREF 설문 지의 검사 문항에 대한 신뢰도를 Chronbach's $\alpha$ 계수를 측정하 여 문항 내적일치도(internal consistency)로 검증하였고, 타당도 를 검증하기 위하여 WHOQOL의 총점과 4개 영역 간에 Pearson 상관계수를 구하였다. 그리고 보청기를 사용하는 노인과 사용하지 않는 노인의 삶의 질은 전반적인 삶의 질 부분과 4 가 지 분야인 신체적 건강영역 심리적 영역, 사회적 관계영역, 환경 영역으로 나누어 점수화하였고, 각 영역의 점수를 0 100점대 척도로 계산하였다. 각 부분은 평균값 \pm 표준편차로 표시하였 으며, 독립표본 $t$ 검증을 이용하여 유의수준 0.05 미만에서 분 석하였다.

\section{RESULTS}

\section{대상자의 인구통계학적인 특성}

총 62 명을 대상으로 하였으며, 60 대 이상의 노인 중 60 대 29명 (44.6\%), 70대 29명(44.6\%), 80대 이상이 4명(6.2\%)이었으며, 청 력은 6 분법으로 계산하였다. 보청기를 착용한 그룹은 오른쪽 평균 $56.18 \mathrm{~dB} \mathrm{HL}$, 왼쪽 평균 $58.56 \mathrm{~dB}$ HL이었으며, 착용하지 않는 그룹은 오른쪽 $60.48 \mathrm{~dB} \mathrm{HL}$, 왼쪽 $58.70 \mathrm{~dB} \mathrm{HL}$ 이었다. 결 혼 여부에서는 통계적으로 유의미한 차이를 보였고 $(t=-4.074$, $p<0.05)$, 경제수준에서도 통계적으로 유의미한 차이를 보였으 나 $(t=-2.932, p<0.05)$, 다른 요인에서는 임상적인 특징에서 두 군 간에 통계적으로 의미 있는 차이는 없었다(Table 1).

\section{보청기 착용 유무에 따른 WHOQOL-BREF 요인별 결과}

보청기를 사용하는 청력손실 노인인 경우가 보청기를 사용 하지 않는 청력손실 노인보다 전반적으로 삶의 질 점수가 높았 으나, 각 세부 요인들을 살펴보면 신체적인 영역에서는 보청기 를 착용 노인 그룹에서는 $17.13 \pm 3.37$ 이었으나 오히려 보청기 를 사용하지 않는 그룹에서는 $18.30 \pm 2.46$ 으로 더 높게 나타났 으며, 사회적인 영역에서도 보청기를 사용하는 노인 그룹에서는 $8.08 \pm 2.46$ 으로 나타났으나, 보청기를 사용하지 않는 그룹에서 는 $11.39 \pm 10.03$ 으로 더 높게 나타났고, 환경적인 요인에서도 보 청기를 사용하지 않는 노인 그룹에서 $20.35 \pm 2.79$ 로 보청기를 사용하는 그룹보다 0.68 보다 더 높게 나타났다. 또한 전체평균 삶의 질 점수에서는 보청기를 사용하는 그룹에서는 $2.95 \pm$ 0.39 였지만, 보청기를 사용하지 않는 그룹에서는 $3.02 \pm 0.49$ 로 0.07 만큼 더 높게 나타났다. 하지만, 통계적으로 유의미하게 차이가 난 것은 전반적인 삶의 질 점수 overall에서만 차이가 났 으며 $(t=3.172, p<0.05)$, 다른 요인들에게서는 통계적으로 유 의미한 차이가 나타나지 않았다(Table 2). 
보청기 착용 유무에 따른 WHOQOL-BREF 세부 문항별 결과

보청기를 사용하는 청력손실 노인과 보청기를 사용하지 않는 청력손실 노인의 WHOQOL-BREF 세부 문항별 결과에서는 '삶의 질을 어떻게 평가 하는가'라는 질문에서 보청기를 사용하
는 청력손실 노인에서는 $3.21 \pm 1.13$ 으로 나타났고, 보청기를 사용하지 않는 청력손실 노인에서는 $2.35 \pm 0.98$ 로 나타났으며 통계적으로 유의미한 차이를 보였다 $(t=3.028, p<0.05)$. 또한 '얼마나 정신을 잘 집중할 수 있는가'라는 질문에 보청기를 사

Table 1. Demographic data

\begin{tabular}{ccc} 
Hearing aid users & Non hearing aid users & \\
\cline { 1 - 2 }$(\mathrm{n}=39)$ & $(\mathrm{n}=23)$ & $(\%)$
\end{tabular}

Hearing level

Mild

Moderate

Moderate to severe

Severe

Profound

Ages

60

70

Over 80

Sex

Male

Female

Education

Illiteracy

Elementary

Middle school

High school

College

University

Graduate university

Marital

Single

Married

Live together

Separate

Divorce

Bereavement

Economic

High

Middle

Low

Number of child visit

Often or over one in a week

Sometimes (over one time in month)

Rare

None

Etc

Health

Very bad

Bad

Middle

Good

Very good
R: 7/L: 4

R: 13/L: 14

R: 11/L: 12

R: 7/L: 6

R: $1 / \mathrm{L}: 3$

22

14

3

18

21

1

12

13

10

1

2

19

2

7

8

3

14

16

9

9

12

13

5
R: $1 / \mathrm{L}$ :

R: 9/L: 14

R: 8/L: 4

R: 4/L: 2

R: $1 / \mathrm{L}: 3$
R:12.9/L: 6.5

R: $35.5 / \mathrm{L}: 45.2$

R: 30.6/L: 25.8

R: $17.7 / \mathrm{L}: 12.9$

R: $3.2 / \mathrm{L}: 9.7$
44.6

44.6

6.2

50.8

44.6

4.6

23.1

29.2

26.2

4.6

7.7

35.4

3.1

13.8

20.0

23.1

24.6

38.5

32.3

21.5

29.2

29.2

15.4

.6

.3

$$
p<0.05
$$

$\begin{array}{ll}6 & 29.2 \\ 5 & 15.4\end{array}$

\begin{tabular}{rrr}
1 & 0 & 1.5 \\
14 & 11 & 38.5 \\
15 & 10 & 38.5 \\
8 & 2 & 15.4 \\
1 & 0 & 1.5 \\
\hline
\end{tabular}


용하는 청력손실 노인은 $3.49 \pm 1.12$ 였고, 보청기를 사용하지 않는 청력손실 노인은 $2.83 \pm 0.78$ 로 나타나 역시 통계적으로 유의미한 차이를 보였다 $(t=2.493, p<0.05)$. 다음으로 '여가활

Table 2. Average scores of main factors for WHOQOL-BREF

\begin{tabular}{lccc}
\hline & \multicolumn{2}{c}{ Mean \pm standard deviation } & \multirow{2}{*}{$p$-value } \\
\cline { 2 - 3 } & $\begin{array}{c}\text { Hearing aid users } \\
(\mathrm{n}=39)\end{array}$ & $\begin{array}{c}\text { Non hearing aid users } \\
(\mathrm{n}=23)\end{array}$ & \\
\hline PHY & $22.13 \pm 4.29$ & $20.04 \pm 3.90$ & $p>0.05$ \\
PSY & $17.13 \pm 3.37$ & $18.30 \pm 2.46$ & \\
SOC & $8.08 \pm 2.46$ & $11.39 \pm 10.03$ & \\
ENV & $19.67 \pm 3.88$ & $20.35 \pm 2.79$ & \\
Score 100 & $54 \pm 15.37$ & $46.7 \pm 13.88$ & \\
Total QOL & $2.95 \pm 0.39$ & $3.02 \pm 0.49$ & \\
Overall & $6.28 \pm 1.53$ & $4.91 \pm 1.86$ & $p<0.05$ \\
\hline
\end{tabular}

WHOQOL-BREF: World Health Organization Quality of Life Assessment Instrument, PHY: physical domain, PSY: psychological domain, SOC: social domain, ENV: environmental domain, Score 100: Scaled score of 100 points, Total QOL: total average score of WHOQOL, Overall: overall quality of life
동 취미생활이나 잘 돌아다니는 가'에서는 통계적으로 유의미 한 차이를 보였고 $(t=-2.178, p<0.05)$, '일을 할 수 있는 능력 에 만족하는가? 문항에 대해서도 통계적으로 유의미한 차이를 보였으며 $(t=2.094, p<0.05)$, '친구로부터의 도움에 만족하는 가?'에서는 통계적으로 유의미한 차이를 보였고 $(t=-2.214, p<$ $0.05)$, ‘부정적인 감정'에 대한 질문에서도 통계적으로 유의미한 차이를 보였다 $(t=2.773, p<0.05)$. 그 외 다른 항목에 대해서 는 모두 통계적으로 유의미한 차이를 보이지 않았다(Table 3).

\section{보청기 착용 유무에 따른 WHOQOL-BREF 요인별 신뢰도와 타당도 결과}

보청기를 사용하는 청력손실 노인의 신뢰도 계수는 각 신체 적 영역, 심리적 영역, 사회적 영역, 환경적 영역에서 각각 0.63 , $0.48,0.47,0.30$ 으로 나타났으며, 타당도 계수는 각각 0.69 , $0.56,0.54,0.77$ 로 나타났다. 반면 보청기를 착용하지 않는 청력 손실 노인의 신뢰도 계수는 각 항목별로 $0.17,0.02,0.54,-0.13$

Table 3. Average scores of detail factors for WHOQOL-BREF

\begin{tabular}{|c|c|c|c|}
\hline \multirow[b]{2}{*}{ Factors } & \multicolumn{2}{|c|}{ Mean \pm standard deviation } & \multirow[b]{2}{*}{$p$-value } \\
\hline & $\begin{array}{l}\text { Hearing aid users } \\
\quad(\mathrm{n}=39)\end{array}$ & $\begin{array}{l}\text { Non hearing aid users } \\
(\mathrm{n}=23)\end{array}$ & \\
\hline How would you rate your quality of life? & $3.21 \pm 1.13$ & $2.35 \pm 0.98$ & $p<0.05$ \\
\hline How happy are you with your health & $3.08 \pm 0.93$ & $2.57 \pm 0.99$ & \\
\hline $\begin{array}{l}\text { To what extent do you think your pain (physical) prevents you from doing what } \\
\text { you need? }\end{array}$ & $2.44 \pm 1.14$ & $2.70 \pm 1.22$ & \\
\hline To what extent do you need some medical treatment to live your daily life? & $2.44 \pm 1.12$ & $2.57 \pm 1.04$ & \\
\hline How much do you enjoy life? & $2.64 \pm 1.20$ & $2.61 \pm 0.99$ & \\
\hline How much do you think your life makes sense? & $2.87 \pm 1.15$ & $2.87 \pm 0.82$ & \\
\hline How much can you concentrate? & $3.49 \pm 1.12$ & $2.83 \pm 0.78$ & $p<0.05$ \\
\hline How safe do you feel in your daily life? & $3.26 \pm 1.02$ & $3.13 \pm 1.06$ & \\
\hline How healthy is your physical environment (climate, noise, pollution, attractions)? & $3.00 \pm 1.10$ & $3.22 \pm 0.60$ & \\
\hline Do you have enough energy for your daily life? & $2.51 \pm 1.29$ & $2.52 \pm 0.95$ & \\
\hline Are you able to accept your physical appearance? & $2.64 \pm 1.04$ & $2.91 \pm 0.90$ & \\
\hline Do you have enough money to pay for your needs? & $2.41 \pm 1.09$ & $2.00 \pm 0.79$ & \\
\hline How available for you is the information you need for your daily life? & $2.64 \pm 1.25$ & $2.43 \pm 0.73$ & \\
\hline To what extent do you have leisure activities? & $1.95 \pm 1.03$ & $2.57 \pm 1.16$ & $p<0.05$ \\
\hline How well can you move? & $3.49 \pm 1.07$ & $2.48 \pm 1.08$ & $p<0.05$ \\
\hline How happy are you with your sleep? & $3.08 \pm 1.11$ & $3.17 \pm 1.03$ & \\
\hline How happy are you with your capacity to perform your daily activities? & $3.03 \pm 1.37$ & $2.83 \pm 1.07$ & \\
\hline How happy are you with your capacity to work? & $2.90 \pm 1.29$ & $2.30 \pm 0.93$ & $p<0.05$ \\
\hline How happy are you with yourself? & $2.82 \pm 1.09$ & $3.30 \pm 1.02$ & \\
\hline $\begin{array}{l}\text { How happy are you with your personal relations (friends, relatives, acquaintances } \\
\text { and colleagues)? }\end{array}$ & $2.87 \pm 1.19$ & $3.39 \pm 0.94$ & \\
\hline How happy are you with your sex life? & $2.46 \pm 1.27$ & $2.61 \pm 0.72$ & \\
\hline How happy are you with the support your get from your friends? & $2.74 \pm 1.14$ & $3.35 \pm 0.83$ & $p<0.05$ \\
\hline How happy are you with the life conditions where you live? & $3.18 \pm 1.12$ & $3.30 \pm 0.82$ & \\
\hline How happy are you with your access to healthcare? & $3.38 \pm 1.14$ & $3.65 \pm 0.65$ & \\
\hline How happy are you with your means of transportation? & $3.23 \pm 1.25$ & $3.70 \pm 0.64$ & \\
\hline $\begin{array}{l}\text { How frequent do you have negative feelings, such as bad mood, hopelessness, } \\
\text { anxiety, depression? }\end{array}$ & $3.15 \pm 1.39$ & $2.22 \pm 1.09$ & $p<0.05$ \\
\hline
\end{tabular}

WHOQOL-BREF: World Health Organization Quality of Life Assessment Instrument 
으로 매우 낮게 나타났고, 타당도 계수는 $0.33,0.44,0.77,0.61$ 로 나타났다. 보청기 사용 청력손실 노인에 대한 전체 신뢰도는 Cronbach's $\alpha=0.76$ 이었고, 보청기 미사용 청력손실 노인에 대 한 신뢰도 Cronbach's $\alpha=0.56$ 이었다(Table 4).

인구통계학적인 요인들에 따른 WHOQOL-BREF 요인별 결과

경제 수준에 따른 결과는 환경적인 요인, 전체 삶의 질 평균

Table 4. Reliability and validity of main factors for WHOQOL-BREF

\begin{tabular}{lccccc}
\hline & \multicolumn{2}{c}{ Hearing aid users $(\mathrm{n}=39)$} & & \multicolumn{2}{c}{ Hearing aid non users $(\mathrm{n}=23)$} \\
\cline { 2 - 3 } \cline { 5 - 5 } & Reliability & Validity & & Reliability & Validity \\
\hline PHY & 0.63 & 0.69 & 0.17 & 0.33 \\
PSY & 0.48 & 0.56 & 0.02 & 0.44 \\
SOC & 0.47 & 0.54 & 0.54 & 0.77 \\
ENV & 0.30 & 0.77 & -0.13 & 0.61 \\
\hline
\end{tabular}

PHY: physical domain, PSY: psychological domain, SOC: social domain, ENV: environmental domain, WHOQOL-BREF: World Health Organization Quality of Life Assessment Instrument
점수에서만 유의미한 차이를 보였고, 성별에서는 심리적 요인과 전반적 삶의 질 평가 항목에서만 유의미한 차이를 보였으며 $(p$ $<0.05)$, 다른 인구통계학적인 요인들에서는 유의미한 차이를 보이지 않았다(Figure 1).

\section{DISCUSSIONS}

의학이 발달되고 생명 연장이 당연시 되면서 살아가는 것에 만 집중했던 시대는 이제 지나갔다. 소득 수준이 높아지고 그러 면서 삶을 어떻게 사는 것이 좋은 것인지, 삶의 질에 대한 관심 이 증가하게 되었다. 지금까지는 주로 사회학 분야에서 삶의 질 에 대한 논의가 있었으나, 최근에는 인구집단의 건강수준과 관 련된 삶의 질의 모니터링과 평가의 중요성이 점차 커지고 있으 며, 건강상태와 삶의 질에 대한 연구들이 많이 진행되고 있다. 특히 노령화가 진행되면서 함께 증가할 것으로 고려되는 시력 장애, 청력장애, 골다공증 등 감각계 및 골격계 질환에 대한 국
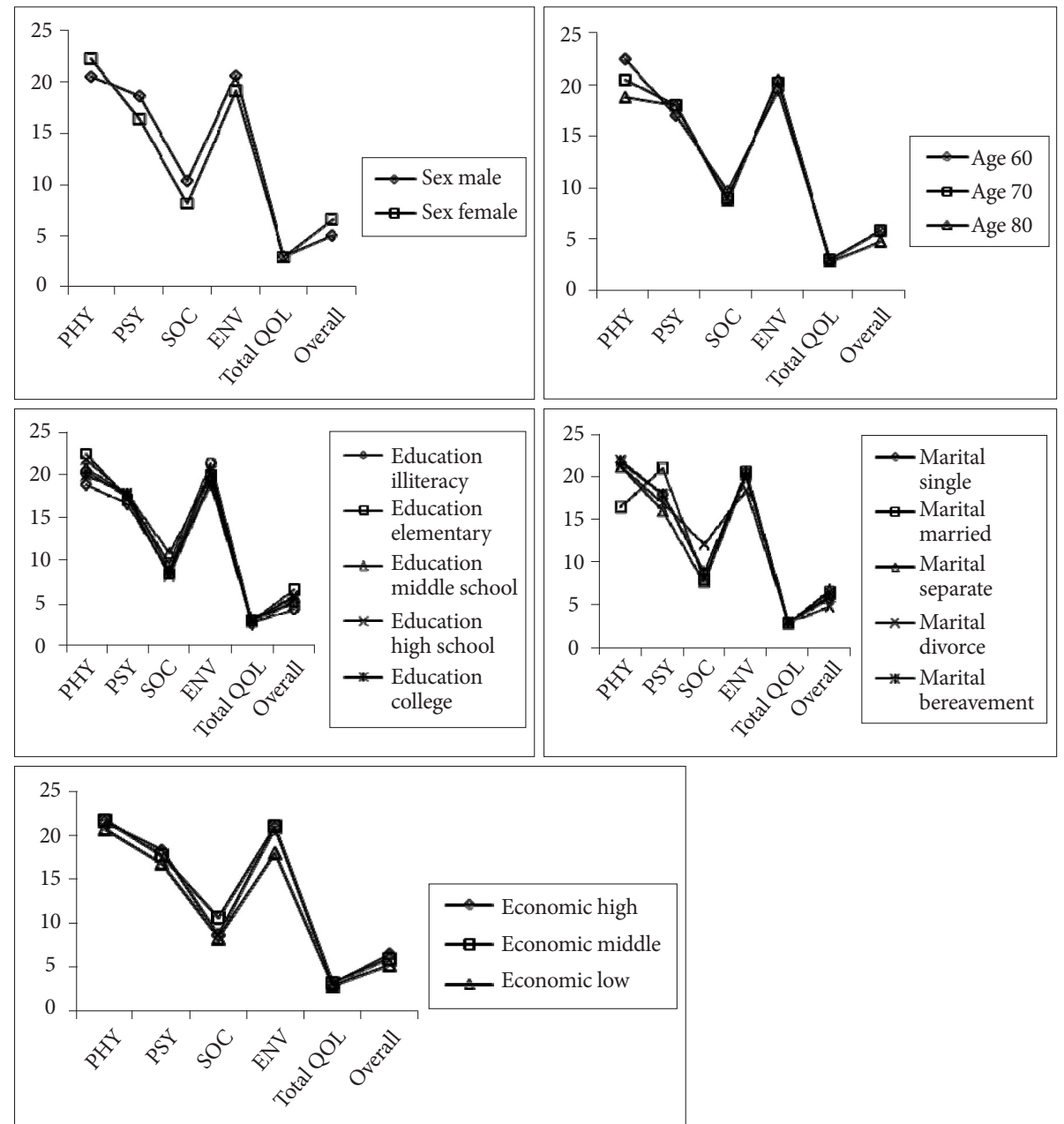

Figure 1. Comparison of WHOQOL quality of life according to demographic characteristics. WHOQOL: World Health Organization Quality of Life Questionnaire. PHY: physical domain, PSY: psychological domain, SOC: social domain, ENV: environmental domain, Total QOL: total average score of WHOQOL, Overall: overall quality of life. 
민의 관심 역시 높아지고 있다. 하지만, 이러한 부분이 삶의 질 에 대한 영향을 직접적으로 주는 것인지 정확히 파악하기 힘들 뿐더러 영향을 주는 부분이 어느 정도인지, 또한 그 부분을 측 정할 수 있는 측정도구가 정확히 없어 통계적인 인용을 할 수 없는 실정이다. 또한 아직까지 청력손실이 있는 대상을 상대로 삶의 질을 평가하는 도구는 없다.

WHOQOL은 전반적인 삶의 질을 평가하는 척도로 알려져 왔다. 많은 선행 연구에서 WHOQOL을 통해 각 계층의 삶의 질을 평가하는 데 많은 도움을 주고 있다. 연령에 따른 도시 지 역 삶의 질에서 $\mathrm{WHOQOL}$ 을 통해 연령이 낮을수록, 남성, 교 육수준이 높은 사람, 가족의 월수입이 많을수록, 직업이 있으 며, 현재 질병이 없는 사람에서 삶의 질이 높게 나타났다(Choi et al., 2012). 노인의 건강 관련 삶의 질에 영향을 미치는 요인은 우울, 사회적 지지, 만성질환의 수였으며 이들 중에서 우울이 가장 큰 영향을 미치는 요인으로 WHOQOL을 통해서 밝혔다 (Oh \& Yi, 2012).

본 연구에서는 표준화한 국문 WHOQOL-BREF (Min et al., 2002)을 사용하였고 전체적인 삶의 질에 대해서는 통계적으로 유의미한 차이가 있는 것으로 나타났다. 하지만, 세부 요인인 신체적 영역, 심리적 영역, 사회적 영역, 환경적 영역 어느 것 하 나에서도 통계적으로 유의미한 차이를 보이지 않았다. 세부 항 목으로 살펴보면, 부정적인 감정, 친구로부터의 도움 만족, 일할 수 있는 능력 만족, 잘 돌아 다니는 것, 여가 취미활동, 얼마나 잘 집중할 수 있나?의 요인에서는 통계적으로 유의미한 차이를 보였다 $(p<0.05)$. 이는 청력손실이 있는 사람이 모두 어려워하 는 내용이다. 즉, 청력손실이 있는 사람이 보청기를 착용하는 것과 착용하지 않는 것에서는 통계적으로 유의미한 차이가 있 다는 것이다. $\mathrm{WHOQOL-BREF}$ 의 전반적인 삶의 질 평가에서 는 통계적으로 차이가 났지만, 100점 점수 전환에서는 통계적 으로 유의미하지 않았고, 다른 세부 요인에서도 대부분에서 차 이가 없는 것으로 나타났다.

본 연구를 통해 청력손실이 있는 노인이 보청기를 사용하는 것과 사용하지 않는 것이 삶의 질에 영향을 주지는 않는다는 것 이다. 하지만 이런 결과는 상반된 결과로 보청기를 착용했을 경 우 전반적으로 삶의 질이 개선되었다고 보고하고 있다(Mondelli \& Souza, 2012). 즉, 청력손실은 있지만, 보청기를 착용함 으로써 잘 들리게 되고 이로 인해 의사소통이 잘 되어 삶의 질 이 개선될 수 있다는 것이다. 그럼, 왜 이렇게 통계적으로 차이 가 나야 되지만, 차이가 없는 것으로 나타난 것일까? 이는 여러 가지 이유로 찾아볼 수 있지만, 주 원인으로 WHOQOL은 청각 장애인들의 삶의 질을 평가하기에는 부족한 척도가 아니라는 결론을 얻을 수 있다. 본 연구의 결과에서처럼 보청기 사용 유무 에 따른 WHOQOL의 타당도를 각 요인별로 분석한 결과 평균
적으로 0.5 이하로 나타났고, 신뢰도는 보청기를 사용한 그룹에 서는 0.7 이상으로 나타났지만, 사용하지 않은 그룹은 0.6 이하 로 나타나 신뢰할 없는 자료가 될 수 있다. 또한 위암수술 환자 와 정상 성인을 대상으로 $\mathrm{WHOQOL-BREF}$ 척도로 평가한 결 과 전반적인 삶의 만족 부분(overall)과 신체적인 영역에서만 통 계적으로 유의미하게 나타났으며(Park, 2006), 여드름이 있는 환자를 대상으로 측정한 결과 전체 삶의 질과 신체적 영역, 정 신적 영역, 사회적 영역에서는 통계적으로 유의미하게 나타났으 나, 전반적인 삶의 질과 환경적인 영역에서는 차이가 없는 것으 로 나타났다(Lee, 2005).

본 연구에서 청력손실이 있는 노인의 경우 WHOQOL 요인별 로는 통계적으로 유의미한 차이가 없었으나, 인구통계학적인 요 인들에서는 경제적 수준, 성별 등에 따라 WHOQOL 요인들과 통계적으로 유의미한 차이를 나타내었다. 이는 청력손실이라는 특수한 변인에 대해서는 WHOQOL 삶의 질 측정 도구로는 평 가가 힘들지만, 일반적인 요인에 대해서는 변별이 가능하다는 결론을 얻을 수 있다. 즉 전반적인 사회 구성원에 대한 평가척 도로 사용하기에 좋으나 특수 계층에 대한 삶의 질 평가로 사 용하기에는 여러 한계점을 가지고 있다. WHOQOL의 한계점을 보면 첫째, 지침서로 사용되고 있는 것은 지적 수준이 높은 대 학생 위주로 나온 결과여서, 지적 수준이나 의식 수준이 떨어지 는 노인들을 대상으로 이 측정도구를 그대로 사용하기에는 무 리가 있으며, $\mathrm{WHOQOL}$ 지침서에서도 언급하였듯이 특정 집 단, 질환에서의 삶의 질을 평가하기 위한 필요성도 제시되었다. 둘째, WHOQOL은 전반적인 삶의 질을 평가하는 도구이다. 신 체적 건강영역, 심리적 영역, 사회적 관계 영역, 환경 영역 등이 다. 이러한 전반적인 삶의 질을 평가하게 되면, 특정 질환, 즉, 눈, 귀, 암, 기타의 질환이 있는 경우에도 일반인과의 삶의 질 평가 에서 유의미한 차이가 나타나지 않을 수도 있다. 특정 질환, 특 정 집단의 경우는 그 집단에 맞는 기준을 가지고 삶의 질을 평 가하여야 정확한 통계 결과를 얻을 수 있다. 셋째, $\mathrm{WHOQOL-}$ $\mathrm{BREF}$ 에서는 4 개의 영역에서 사회적 관계 영역에서 삶의 질을 평가하는 공헌도에서 통계학적으로 유의미 하지 않게 나타났으 며, 심리적 영역과 환경적 영역 또한 통계적으로는 유의미하게 나타났지만, 신체적 건강부분보다는 낮게 나타나 삶의 질을 각 영역별로 정확하게 분석하는 데에는 한계점을 보였다. 그리고 사회적 관계 영역 부분은 청각장애인에게는 매우 중요한 부분 으로 사회적 관계에서 만족이 되지 않거나 문제가 있으면 그것 이 삶의 질과 연결되기 때문에 특히나 이러한 부분에서 통계적 으로 유의미하지 않게 나타난 것은 청각난청인을 위한 삶의 질 측정도구 개발의 필요성을 뒷받침해준다. 또한, 특히 노인성 난 청에 의한 삶의 질을 평가할 때는 노인의 여러 다른 요인으로 인 한 여기서 애기하는 여러 다른 요인들은 청력손실이 아닌 경제적 
요인, 다른 질환 등으로 인해 삶의 질에 영향을 줄 수도 있으며, 노인들은 무기력, 우울, 초조, 긴장, 불안감 등의 저조한 기분 상 태를 느끼게 될 것인데, 이러한 심리적 변화는 삶의 질에 대한 지 대한 영향을 줄 수 있는 요인이 된다(Park, 2006). WHOQOL 측 정도구는 전반적인 삶의 질을 평가하는 도구로 청력손실로 인 한 삶의 질이 아닌 다른 요인으로 인해 결과에 영향을 미칠 수 있다. 마지막으로 WHOQOL 지침서에서 한국판 WHOQOL 표 준형과 $\mathrm{WHOQOL}-\mathrm{BREF}$ 는 더 빠르고 간편하게 영역 점수를 계산할 수 있게 해 주고 또한 그 타당도와 신뢰성이 높으며, 일 차적으로 삶의 질에 대한 평가가 가능하지만, 특정 집단, 특정 질환에 대한 연구일 경우에는 세부적인 측정도구 개발이 필요 하다고 하였다.

따라서 청력손실을 가진 노인들의 증가와 그들의 사회적인 고 립을 고려해 볼 때 하루 빨리 그들의 삶의 질을 과학적으로 측정 하고 평가함으로써 삶의 질을 좀 더 정확히 파악하고 이를 토대 로 삶의 질을 증진시킬 수 있으며(Min et al., 2002), 그들의 삶의 질을 정확히 평가하고 보청기 등이 삶의 질을 높이는 데 도움이 된다면 사회적인 지원을 통해 청각장애 노인의 삶을 보다 윤택 하게 할 필요성이 있을 것이다.

이번 연구의 제한점으로 연구대상자들의 수가 62명으로 신뢰 도 타당도를 검증하기에 적은 수이므로 대규모 청력손실이 있 는 노인들을 대상으로 한 연구를 통해 확인하는 것이 필요할 것 이며, 청각장애인이라는 특수 부분과 노인이라는 특수계층을 고려한 삶의 질 측정도구 개발이 시급히 필요하다고 생각된다.

중심 단어 : 세계보건기구 삶의 질 척도 단축형·청력손실· 보청기·삶의 질.

\section{REFERENCES}

Beck, A. T., Steer, R. A., \& Brown, G. K. (1996). Manual for the Beck Depres- sion Inventory-II. San Antonio, TX: Psychological Corporation.

Choi, J. S., Lee, E., So, A., \& Lee, K. S. (2012). Quality of life in the urban adults by age. Journal of Muscle and Joint Health, 19(3), 362-372.

Han, C. W., Lee, E. J., Sekita, Y., \& Kohzuki, M. (2009). Use of structural equation modeling to test construct validity of the sf- 36 health survey among community-dwelling elderly in Korea. Korea Care Management Research, 4, 45-59.

Kang, C. W. \& Lee, J. W. (2006). A study on the life satisfaction to improve the quality of life of the elderly with hearing impairment. Journal of Speech and Hearing Disorders, 15(2), 75-91.

Kim, S. J. (2009). Hearing status, mood state and quality of life elderly (unpublished master's thesis). Hanyang University, Seoul.

Lee, S. H. (2005). Quality of life patients with acne (unpublished master's thesis). Hallym University, Chuncheon.

Lim, J. Y. (2006). Quality of life (SF-36) and Its associated factors among some elderly residents in a community (unpublished master's thesis). Chosun University, Gwangju.

Lin, F. R., Metter, E. J., O’Brien, R. J., Resnick, S. M., Zonderman, A. B., \& Ferrucci, L. (2011). Hearing loss and incident dementia. Archives of Neurology, 68(2), 214-220.

Min, S. K., Kim, K. I., \& Park, I. H. (2002). Korean version of WHOQOL. Seoul: Hana Medical Publishers.

Ministry of Health \& Welfare. (2006). Korea institute for health and social affairs (pp. 43-60). Seoul: Ministry of Health and Welfare.

Mondelli, M. F. \& Souza, P. J. (2012). Quality of life in elderly adults before and after hearing aid fitting. Brazilian Journal of Otorhinolaryngology, 78(3), 49-56.

Oh, J. H. \& Yi, M. S. (2012). Nursing practice: Factors that affect health-related quality of life in community-dwelling older adults. Perspectives in Nursing Science, 9(2), 102-110.

Park, S. G. (2006). The Relationship between elderyl people's mental health and quality of life. The Korean Journal of Health Psychology, 11(4), 785796.

Statistics Korea (2015). Statistics of old people for 2015. Statistics Korea. Retrieved from http://kostat.go.kr/portal/korea/kor_nw/3/index.board? bmode $=$ read\&aSeq $=348566$.

The WHOQOL Group (1998). The World Health Organization Quality of Life Assessment (WHOQOL): Development and general psychometric properties. Social Science and Medicine, 46(12), 1569-1585.

United Nations (UN). Dept. of Economic and Social Affairs. Population Division. (2005). World population prospects: the 2004 revision. New York: United Nations. 